\title{
Adsorption of uremic toxins using biochar for dialysate regeneration
}

\author{
Wei Wang ${ }^{1,2} \cdot$ Zhijuan Wang ${ }^{2,3} \cdot{\text { Kai } \mathrm{Li}^{1,2} \cdot \text { Yuxin } \mathrm{Liu}^{1,2} \cdot \text { Delong Xie }^{1,2} \cdot \text { Shaoyun Shan }}^{1,2} \cdot$ Liang He $^{1,2} \cdot$ Yi Mei $^{1,2,4}$
}

Received: 9 July 2021 / Revised: 1 September 2021 / Accepted: 8 September 2021

(C) The Author(s), under exclusive licence to Springer-Verlag GmbH Germany, part of Springer Nature 2021

\begin{abstract}
Numerous studies have shown that patients with COVID-19 have a high incidence of renal dysfunction. However, the dialysis supplies, including dialysates, are also severely inadequate in hospitals at the pandemic centers. Therefore, there is an urgent need to develop materials that can efficiently and rapidly remove toxins and thus regenerate dialysate to make this vital resource remains readily available. In this work, by simple carbonization and activation treatment, the porous activated carbon from waste rubber seed shell (RAC) was prepared. The adsorption results showed that the maximum adsorption capacities of the obtained RAC for creatinine and uric acid were $430 \mathrm{mg} / \mathrm{g}$ and $504 \mathrm{mg} / \mathrm{g}$, respectively. Significantly, the adsorption process can be close to the equilibrium state within $0.5 \mathrm{~h}$, which proved the ultra-fast adsorption response capacity of RAC. Further, the thermodynamics analysis results showed that both the creatinine and uric acid adsorption processes were monolayer, exothermic, and spontaneous. The adsorption kinetics results indicated that the adsorption process of the two uremic toxins followed the pseudo-second-order rate model and was dominated by chemisorption. The instrument analysis results reflected the efficient adsorption of the RAC for the above uremic toxins which might be due to the dipole-dipole interaction between the dipolar oxygen-containing groups of the surface of RAC and the dipoles of the toxins. Moreover, the formed hydrogen bonds between the oxygen groups and the toxins also played an important role. In all, the as-prepared RAC has the potential to efficiently remove major toxins from the dialysate and can be used in in vitro dialysis of numerous patients during the current COVID-19 pandemic.
\end{abstract}

Keywords Creatinine $\cdot$ Uric acid $\cdot$ Adsorption mechanism $\cdot$ Rubber seed shell activated carbon

\section{Introduction}

At present, coronavirus disease 2019 (COVID-19) is rampaging around the world, which seriously threatens the survival of mankind. Early studies of patients with COVID-19 have found a high incidence of kidney function

Liang $\mathrm{He}$

heliang@kust.edu.cn

Yi Mei

meiyi412@126.com

1 Faculty of Chemical Engineering, Kunming University of Science and Technology, Kunming, China

2 Higher Educational Key Laboratory for Phosphorus Chemical Engineering of Yunnan Province, Kunming, China

3 Faculty of Environmental Science and Engineering, Kunming University of Science and Technology, Kunming, China

$4 \quad$ Yunnan Provincial Key Laboratory of Energy Saving in Phosphorus Chemical Engineering and New Phosphorus Materials, Kunming, China abnormalities [1, 2]. Concerningly, in hospitals in the COVID-19 pandemic area, the dialysate is increasingly in short supply, leaving partial patients with renal failure without effective dialysis treatment [3]. Generally, dialysate is stored as a concentrated solution that before use, it needs to be diluted with pure water [4]. Traditionally, hemodialysis treatment requires large, bulky machines to filter blood more than three times weekly and requires at least hundreds of liters of dialysate per treatment [5]. This is one reason why the above treatment can be difficult at home. Luckily, recycling dialysis waste liquid can greatly reduce the consumption of pure water during dialysis treatment and can also make the dialysis equipment smaller and more conducive to family dialysis treatment $[6,7]$. Currently, the latest regeneration modular circulating dialysis (REDY) system combines sorbent and enzyme technology to effectively remove creatinine and uric acid from dialysis waste liquid and is the basis of many modern WAK prototypes [8]. The REDY regeneration unit consists of multiple sorbent layers: activated carbon, urease, zirconium phosphate, and finally zirconium oxide 
and zirconium carbonate to remove organic compounds (e.g., creatinine and uric acid), urea, cations (e.g., potassium, ammonium), and phosphates, respectively [9]. However, the drawbacks to this method include the poor adsorption of activated carbon for creatinine and uric acid and preparation of immobilized urease as well as the high cost of zirconium phosphate [10]. These may limit the ability to provide hemodialysis treatment to large numbers of patients during the COVID-19 pandemic. Thus, ultra-high adsorption capacity activated carbon should be developed in order for to efficiently remove uremic toxins from the COVID-19 patient.

An activated carbon with higher adsorption capacity, except the task-specific internal structure (e.g., the high surface area, large porosity, and well-developed internal pore structure consisting of micro-, meso-, and macropores) adsorbent, also has some surface functional groups (e.g., carboxyl, carbonyl, and hydroxyl groups) which can significantly link with uremic toxin by dipole-dipole interaction and hydrogen bonding [11-14]. In order to have the above-mentioned internal structure and surface chemistry of activated carbon, with the process of synthesis to be of uppermost importance. Conventional methods for morphological and structural modulation of activated carbon include physical activation, chemical activation, and physical-chemical activation $[15,16]$. During physical activation, large amounts of pores in activated carbon could be obtained only by carbonizing precursors under an inert atmosphere and then followed by activating in the presence of suitable gasifying agents $\left(\mathrm{CO}_{2}\right.$ or steam) at a high-temperature range of $600-1200{ }^{\circ} \mathrm{C}$ [17]. By contrast, chemical activation and physicochemical activation allow relatively mild preparation temperatures $\left(400-800{ }^{\circ} \mathrm{C}\right)$ in the presence of chemical activators (e.g., $\mathrm{ZnCl}_{2}, \mathrm{KOH}, \mathrm{K}_{2} \mathrm{CO}_{3}$, and other molten salts) $[18,19]$. The activator etches the precursor to form a 3D carbon skeleton while decomposing the tar and amorphous carbon clogged in the pores to form an abundant pore structure [20]. After the removal of the above-mentioned intercalated metal compounds, further rich micro- and mesoporous structures can be formed. Moreover, the economical operating cost from the use of low-cost adsorbents is a major concern for practical deployment. Thus, there has been a growing interest to produce activated carbon from less expensive abundant and renewable raw materials such as plants and agricultural residues [21]. It is reported that activated carbon has been successfully prepared from various biomass wastes by chemical or physicochemical activation methods, such as coconut shell [22], pine cone [23], orange peel [24], pomegranate peel [25], and rice husk[16], and has good adsorption properties for various inorganic or organic compounds. Meanwhile, the type and nature of raw materials used also affect the structure and surface chemical properties of activated carbon [26]. As a type of precursor for carbon material, rubber seed shell, the by-product in rubber planting industries, is low cost, has high lignin content, has low ash content, and has dense surface morphology, which has enormous application potential in the preparation of adsorbents with high adsorption capacity [27].

Hence, in this study, with the physical-chemical activation method, the rubber seed shell has been converted into activated carbon-based adsorbents for the adsorption of uremic toxin in an aqueous solution. The obtained porous carbon has reasonable pore distribution and abundant oxygen-containing functional groups, which could promote the formation of abundant active sites and facilitates high-level diffusion kinetics and ultra-high adsorption capacity. The results of adsorption experiments indicated that this RAC was envisioned to have excellent performance in adsorbing several typical uremic toxins in aqueous solutions, including creatinine $\left(\mathrm{C}_{4} \mathrm{H}_{7} \mathrm{~N}_{3} \mathrm{O}\right)$ and uric acid $\left(\mathrm{C}_{5} \mathrm{H}_{4} \mathrm{~N}_{4} \mathrm{O}_{3}\right)$ with fast adsorption and ultra-high adsorption capacity. Furthermore, we perform kinetics, isotherms, and thermodynamic analyses of adsorption to understand the mechanism of adsorption of urea and creatinine uric acid onto RAC. This work expects that this will offer a low-cost adsorbent, enabling the regeneration of dialysate for use in the care of COVID-19 patients with kidney failure.

\section{Experimental}

\subsection{Materials}

The rubber seed shell as a by-product of natural rubber harvested came from Xishuangbanna Huakun Biotechnology Co. Ltd., Yunnan, China. Sodium hydroxide, hydrochloric acid, nitric acid, potassium hydroxide, ammonium hydroxide, creatinine, and uric acid were purchased from Shanghai Aladdin Biochemical Technology Co., Ltd (China). All the chemicals were directly utilized after purchase without further purification.

\subsection{Preparation of RAC adsorbents}

The dried rubber seed shell was ground and sieved to mesh between 40 and 60 . The dried rubber seed shell powders were carbonized in $\mathrm{N}_{2}$ atmosphere $(100 \mathrm{~mL} / \mathrm{min})$ at $500{ }^{\circ} \mathrm{C}$ for $1 \mathrm{~h}$ at a ramp rate $5{ }^{\circ} \mathrm{C} / \mathrm{min}$. After cooling down naturally, the rubber seed shell powders $(2 \mathrm{~g})$ and $\mathrm{KOH}(8 \mathrm{~g})$ were sufficiently ground, followed by calcining the mixture in $\mathrm{N}_{2}$ atmosphere $(100 \mathrm{~mL} / \mathrm{min})$ at $800^{\circ} \mathrm{C}$ for $1 \mathrm{~h}$ at a ramp rate of $5{ }^{\circ} \mathrm{C} / \mathrm{min}$, and then soaking in $\mathrm{HNO}_{3}$ to remove $\mathrm{KOH}$. Subsequently, the RAC mixture was separated by suction filtration and washed with deionized water until the $\mathrm{pH}$ value reached 7. Then, it was boiled in $1 \mathrm{M}$ hydrochloric acid and $1 \mathrm{M}$ sodium hydroxide solution four times alternately for $2 \mathrm{~h}$ each for reducing the heavy metal content in activated 
carbon and then washed to neutral with deionized water. Finally, the obtained RAC was dried at $80{ }^{\circ} \mathrm{C}$ for $12 \mathrm{~h}$.

\subsection{Batch adsorption experiments}

Batch experiment studies were carried out by taking $25 \mathrm{~mL}$ of the solution with the desired concentration of creatinine or uric acid (100-1200 mg/L) and weight of RAC $(0.4 \mathrm{~g} / \mathrm{L})$ in $100 \mathrm{~mL}$ of brown glass bottle. All the samples were shaken at $200 \mathrm{rpm}$ for $1 \sim 3 \mathrm{~h}$ at different temperatures $(298.15 \mathrm{~K}$, $308.15 \mathrm{~K}$, and $318.15 \mathrm{~K}$ ). After adsorption experiments, the suspensions were filtered through $0.22 \mu \mathrm{m}$ of Nylon membrane. The creatinine and uric acid concentrations after adsorption were measured by UV-Vis spectroscopy (Agilent, UV8453, USA) at 234 and $295 \mathrm{~nm}$, respectively. The removal efficiency and the adsorption capacity could be calculated by the following equations:

$\eta=\left(C_{0}-C_{e}\right) / C_{0} \times 100 \%$

$\mathrm{qe}=\left(C_{0}-C_{e}\right) / m \times V$

where $C_{0}$ and $C_{e}$ are the initial and equilibrium concentration of corresponding uremic toxins in the solution $(\mathrm{mg} / \mathrm{L})$. $m$ is the dosage of RAC ( $\mathrm{g})$ and $V$ is the volume of the uremic toxin-containing solution (L).

\subsection{Quality inspection of RAC}

In order to ensure that the safety of the medicinal carbon prepared in this study, its quality was tested firstly according to the reference standard was Chinese pharmacopeia (Page 718, Part II, 2015). A total of 11 items were detected, including $\mathrm{pH}$, chloride, sulfate, non-carbide, iron salt, zinc salt, and other heavy metals, acidic-soluble matter, dry weight loss, incineration residue, adhesion, etc., are limited checks.

\subsection{Characterization of RAC}

Using the micromeritics (TriStar-3020, USA) surface area pore size analyzer at $77.3 \mathrm{~K}$, the nitrogen adsorption and desorption isotherms were obtained. The SEM image of the sample was obtained by a high-resolution field emission scanning electron microscope from Zeiss (Gemini300, Germany). SEM-EDS was used to analyze the surface elements of RAC. Surface functional group analysis was performed using Fourier transform infrared spectroscopy (FTIR, Thermo Scientific Nicolet iS50, USA). The X-ray diffraction (XRD, Rigaku Ultima IV, Japan) was applied for the demonstration of the XRD pattern of the sorbent materials. Using the X-ray photoelectron spectroscopy (XPS, Thermo Scientific K-Alpha, USA) instrument, the electronic binding energy of the sample was obtained.

\section{Results and discussion}

\subsection{Quality inspection analysis of RAC}

Various impurities in adsorbent can be harmful to human health. Therefore, in this work, following the 2015 edition of Chinese Pharmacopoeia, the quality studies on adsorbent are carried out, including characteristics, identification, examination, dissolution, and content assay, and the results are shown in Table 1. It can be observed that after carbonization, activation, and washing, the chloride and sulfate content of this adsorbent is well below $0.05 \%$ and does not lead to cellular osmolarity imbalance and diarrhea problems [28]. Moreover, the contents of iron, zinc, lead, and other heavy metal salts are lower than the limits of impurities in the Chinese Pharmacopoeia, indicating that the adsorbent will not cause related diseases, such as liver failure, hypertension, reduced autoimmune function, and delayed development of the central nervous system [29]. Meanwhile, the contents

Table 1 Quality inspection results of RAC

\begin{tabular}{llll}
\hline Project & Unit & Reference standard & Experimental result \\
\hline $\mathrm{pH}$ & - & Neutral & Neutral \\
Chloride & $\%$ & $\leq 0.1$ & $5.884^{*} 10^{-5}$ \\
Sulfate & $\%$ & $\leq 0.05$ & $2.546^{*} 10^{-5}$ \\
Non-carbide & - & The filtrate was lighter than the control & The filtrate showed no color \\
Dissolved matter in acid & $\mathrm{mg}$ & $\leq 10$ & 1.70 \\
Loss on drying & $\%$ & $\leq 10.0$ & 1.64 \\
Burning residue & $\%$ & $\leq 3.0$ & 0.58 \\
Ferric salt & $\%$ & $\leq 0.05$ & 0.00456 \\
Zinc salt & $\%$ & $\leq 0.02$ & $0.0020 \%$ \\
Heavy metals $($ by $\mathrm{Pb})$ & $\mathrm{ppm}$ & $\leq 30$ & $\leq 17$ \\
Suction force & $\mathrm{mL}$ & $\geq 1.2$ & $\geq 3.7$
\end{tabular}


of uncarbonized and dissolved matter in acid also fulfilled the standards of Chinese Pharmacopoeia, indicating that the adsorbent prepared in this study has excellent stability under acid-base conditions [30]. In addition, the adsorption capacity of the adsorbent prepared in this study was much higher than that prescribed by the Chinese Pharmacopoeia. In conclusion, all the quality indexes of the activated carbon prepared in this study met the quality requirements of the Chinese Pharmacopoeia.

\subsection{Structure and morphological analysis of RAC}

Firstly, the raw material (rubber seed shell) and the prepared RAC were analyzed by SEM. As shown in Fig. 1, the rubber seed shell (Fig. 1A) had dense structure, smooth surface, and no obvious holes. However, the prepared RAC shows regular cavity structure and uniform size distribution, as seen in Fig. 1B-D, which indicated that abundant pores were formed in the rubber seed shells after physicochemical activation.
According to the literature [31], due to the diffusion of the pyrolysis gases, e.g., $\mathrm{H}_{2} \mathrm{O}, \mathrm{CO}, \mathrm{CO}_{2}$, and $\mathrm{CH}_{4}$, a large number of micropores will be generated. Then, the remaining carbon atoms will be randomly cyclized and condensed to form polycyclic aromatic carbon (PAC) structure or condensed to form graphite microcrystals [32]. Meanwhile, the carbon matrix was etched by $\mathrm{KOH}$ to form a three-dimensional porous carbon skeleton [16]. The EDS mapping analysis results of RAC have been described in Fig. 1E-I. The results of EDS showed that the RAC adsorbent contained C ( $90.57 \mathrm{wt} \%)$, O (9.13 wt \%), and $\mathrm{N}(0.3 \mathrm{wt} \%)$ elements. The spectra of $\mathrm{O}$ atoms directly reflected the existence of abundant oxygen-containing groups, e.g., $\mathrm{C}=\mathrm{O},-\mathrm{OH}, \mathrm{C}-\mathrm{O}-\mathrm{C}$, on the carbon skeleton of RAC, which provides abundant active sites for adsorption of creatinine and uric acid [15]. According to the literature, the rubber seed shell raw material contains a toxic compound, i.e., cyanogen glycoside, which can provide elements $\mathrm{N}$ after thermal decomposition at high temperature and oxygen-limited atmosphere [33].
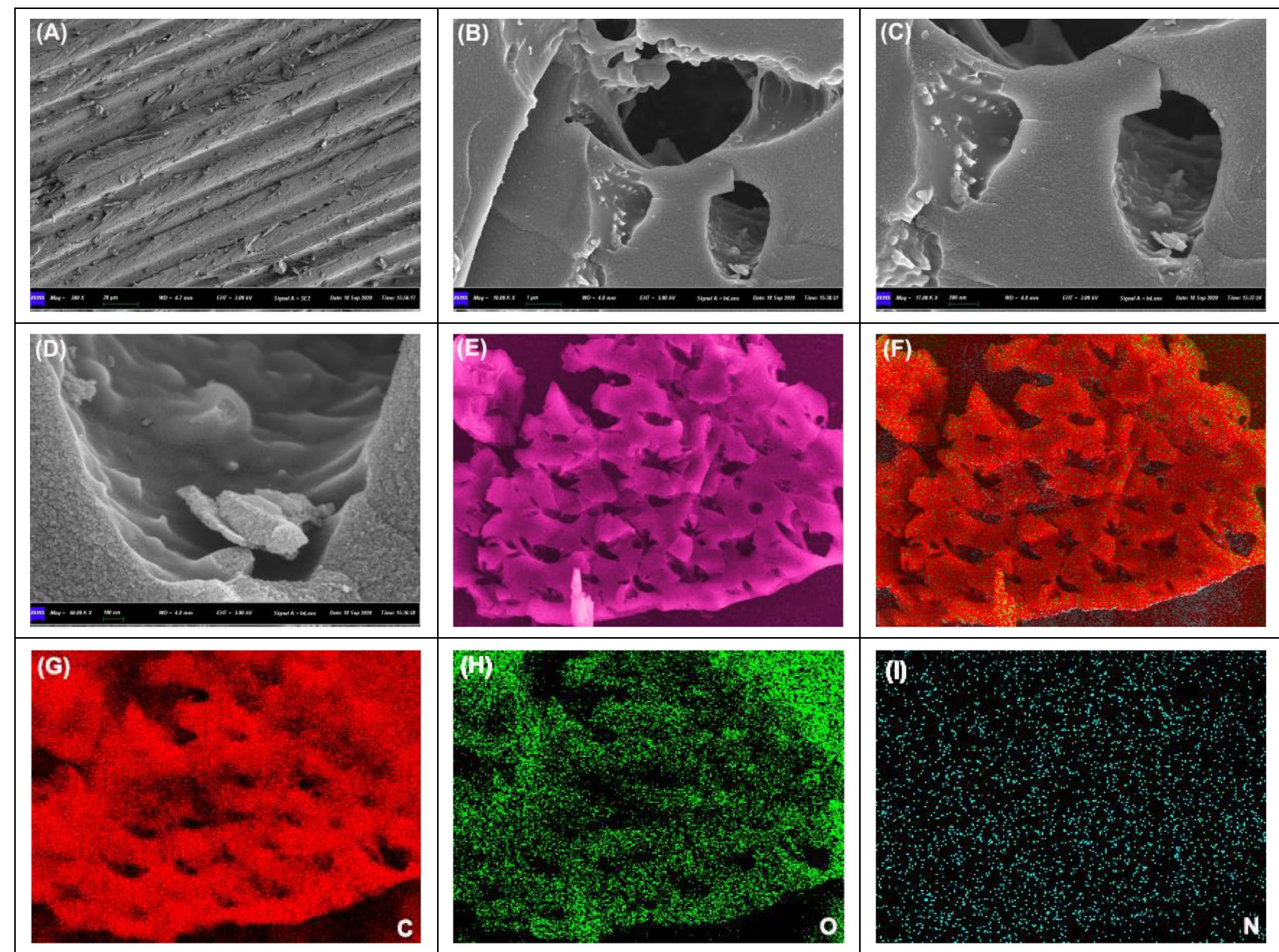

Fig. 1 SEM images of raw material (A) and RAC adsorbent (B), (C), (D); EDS mapping analysis area (E), (F), and the elemental mapping of (G) $\mathrm{C},(\mathbf{H}) \mathrm{O}$, and $(\mathbf{I}) \mathrm{N}$ 
However, after the carbon activation treatment, elemental $\mathrm{N}$ may be present on the activated carbon in the form of graphitic nitrogen, pyridine nitrogen, or pyrrole nitrogen, which will be further analyzed later [34].

The reasonable hierarchical structure and pore size distribution of activated carbon facilitated the adsorption of organic micropollutants. As shown in the Fig. 2A, the nitrogen adsorption/desorption isotherms observe type I, indicating the microporosity of the samples with uniform pore sizes [35]. Meanwhile, the Brunner-Emmet-Teller and Horvath-Kawazoe methods have been used to calculate the pore size distributions, and the conclusions are presented in Fig. 2B; the BET specific surface area, pore diameter, and pore volume of RAC were $2348 \mathrm{~m}^{2} / \mathrm{g}, 3.43 \mathrm{~nm}$, and 1.41 $\mathrm{m}^{3} / \mathrm{g}$, respectively. Obviously, the plentiful pores of the RAC were mainly distributed at $3 \mathrm{~nm}$, indicating that the RAC possessed a good deal of narrow mesopore and uniform pore diameter distribution. In this work, the effective molecular diameters of the two typical uremic toxins were less than $0.7 \mathrm{~nm}$ and also less than 0.5 times the narrow mesoporous diameter [36]. Thus, the above uremic toxin model pollutants could reach almost the inner pores of the RAC. The FTIR spectroscopy was carried out to confirm the surface functional groups of RAC (Fig. 2C). The characteristic absorption peak at 3435 and $1625 \mathrm{~cm}^{-1}$ was attributed to the stretching vibration of the hydroxyl group, carbonyl, and the skeletal vibration of aromatic $\mathrm{C}=\mathrm{C}$ bonds [37], while the adsorption bands of 2930 and $2853 \mathrm{~cm}^{-1}$ could be attributed to $-\mathrm{CH}_{2}$ and $-\mathrm{CH}_{3}$ groups [38]. These results indicated that the surface of the sample was rich oxygen-containing functional groups, which might form hydrogen bonds with creatinine and uric acid. Meanwhile, the dipole-dipole interaction
(A)

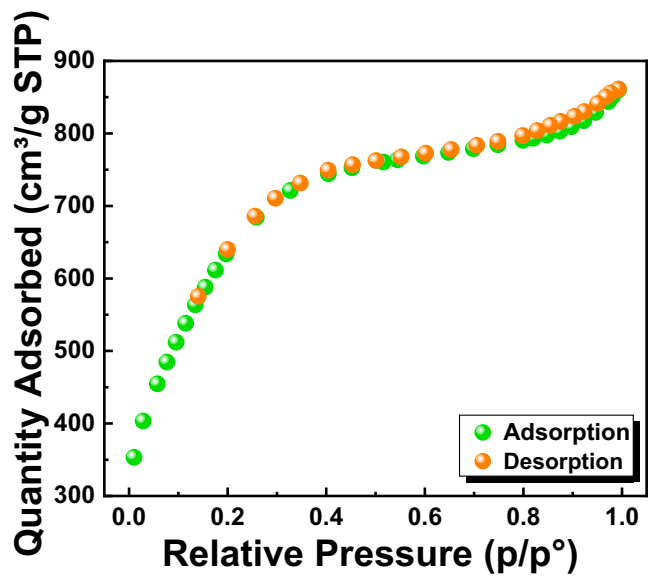

(B)

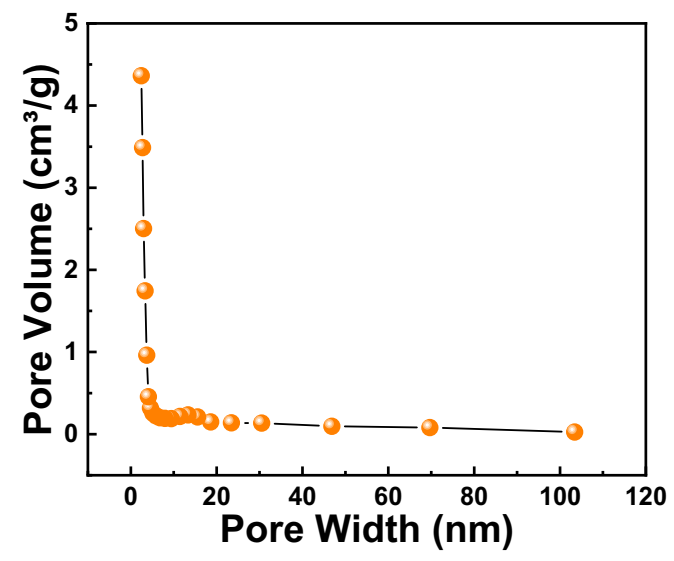

(C)

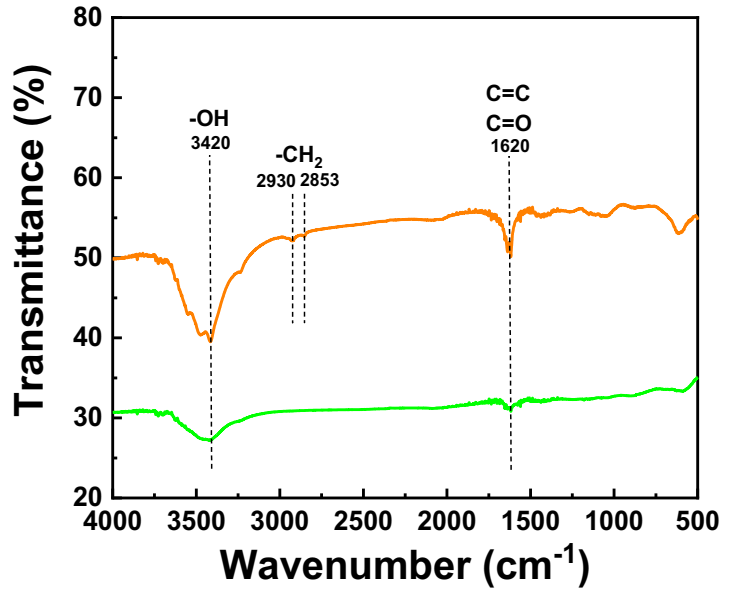

(D)

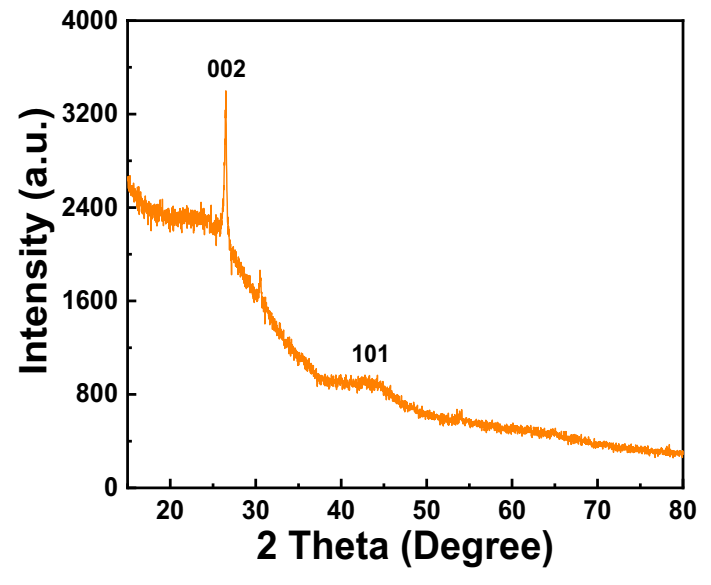

Fig. 2 Nitrogen adsorption-desorption (A), pore size distribution (B), FTIR (C), and XRD patterns of RAC (D) 
between the dipoles of the oxygen surface groups and the uremic toxin is also considered to facilitate the adsorption. The XRD patterns showed broad peaks at $23^{\circ}$ and $43^{\circ}$, which corresponded to the (002) and (100) crystal plane diffraction peaks of graphite crystallite (Fig. 2D) [39]. In addition, the low intensity and broad peak of RAC indicated that the RAC sample was a porous carbon mixture consisting of microcrystalline graphite and amorphous carbon.

To further analyze the surface chemical composition of RAC, X-ray photoelectron spectroscopy has been employed. As shown in Fig. 3A, the atomic ratio of carbon, nitrogen, and oxygen in RAC was $92.3 \%, 0.71 \%$, and $6.99 \%$, respectively. The XPS spectrum of $\mathrm{C} 1 \mathrm{~s}$ is shown in Fig. 3B. The strong peaks at $284.08 \mathrm{eV}$ and $285.03 \mathrm{eV}$ were assigned to the $\mathrm{sp}^{2}$-bonded carbon and $\mathrm{sp}^{3}$-bonded carbon of RAC, respectively. The results indicate that RAC has a graphitelike structure, which is consistent with the XRD analysis results [40]. The peaks at $288.58 \mathrm{eV}$ belonged to $-\mathrm{COOH}$, which can form a hydrogen bond with creatinine and uric acid [38]. The N $1 \mathrm{~s}$ spectrum in Fig. 3C could be fitted into the graphitic type of $\mathrm{N}$, indicating that the element $\mathrm{N}$ in the RAC is mainly present in the form of graphitic nitrogen [34]. The $\mathrm{O} 1 \mathrm{~s}$ region spectrum is presented in Fig. 3D and shows three distinct peaks centered at $530.88 \mathrm{eV}, 532.58 \mathrm{eV}$, and $532.6 \mathrm{eV}$, which corresponded to $-\mathrm{COOH}, \mathrm{C}-\mathrm{O}-\mathrm{C}$, and $\mathrm{C}-\mathrm{OH}$ functional groups, respectively [41, 42]. Moreover, $-\mathrm{COOH}$ and $-\mathrm{OH}$ functional groups can form hydrogen bonds with creatinine and uric acid.

\subsection{Studies on the adsorption behavior of creatinine}

An adsorption isotherm describes the relationship between the amount of adsorbate $\left(Q_{e}\right)$ taken up by the adsorbent and the adsorbate concentration $\left(C_{e}\right)$ remaining in the solution when equilibrium is reached. The parameters

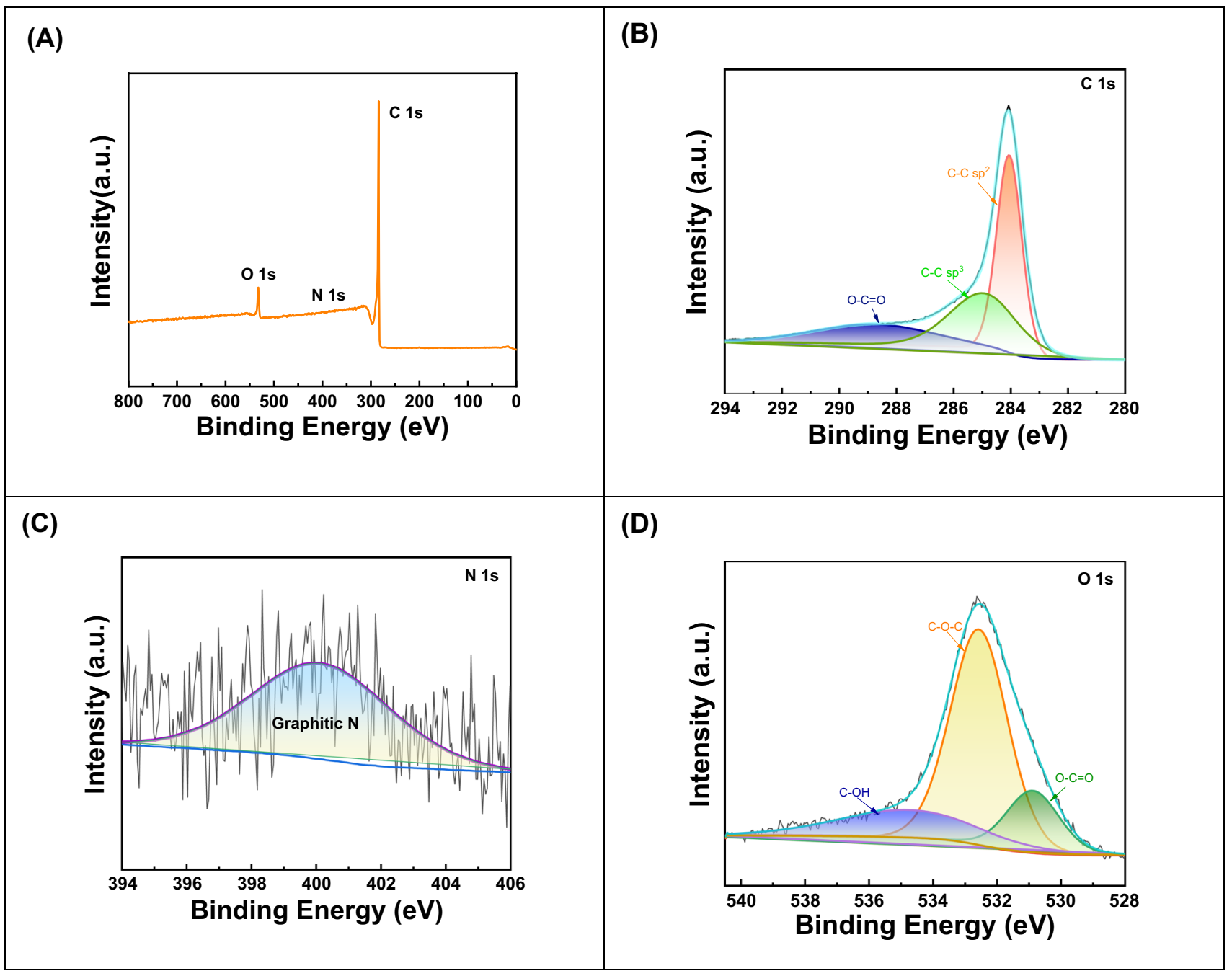

Fig. 3 XPS survey (A) and the high-resolution XPS C 1 s (B), N 1 s (C), and O 1 s (D) spectra of RAC 
determined by adsorption equilibrium models give insight into the adsorption mechanism, surface properties of the adsorbent, and affinity between adsorbent and adsorbate. In this work, the adsorption isotherms of creatinine from 298.15 to $318.15 \mathrm{~K}$ were constructed in order to determine the thermodynamic parameters. From Fig. 4A, the maximum adsorption capacity of creatinine at $298.15 \mathrm{~K}$, $308.15 \mathrm{~K}$, and $318.15 \mathrm{~K}$ for RAC is $430 \mathrm{mg} / \mathrm{g}, 393 \mathrm{mg} / \mathrm{g}$, and $377 \mathrm{mg} / \mathrm{g}$, respectively. The increase of adsorption equilibrium capacity was observed with increasing the initial concentration of creatinine solution at all temperatures, suggesting that a high initial concentration provides an important driving force to overcome all mass transfer resistances of adsorbates between the aqueous and solid phases [43]. Table 5 presents a comparison between the maximum uptake capacities $\left(Q_{m}\right)$ of various adsorbents reported in the literature and the values obtained in the present work. Surprisingly, compared to other reported absorbents, RAC performed best in the adsorption of creatinine and uric acid, indicating that RAC has showed excellent adsorption performance in adsorption of uremic toxin. In this work, the experimental data were processed with Langmuir and Freundlich adsorption isotherms. The Langmuir and Freundlich formulas were expressed by Eqs. (3) and (4), respectively[44].

$\frac{C_{e}}{q_{e}}=\frac{C_{e}}{q_{m}}+\frac{1}{q_{m} K_{L}}$

$\ln \left(q_{e}\right)=\frac{1}{n} \ln \left(C_{e}\right)+\ln \left(K_{F}\right)$

In Eqs. (3) and (4), $q_{e}(\mathrm{mg} / \mathrm{g})$ and $C_{e}(\mathrm{mg} / \mathrm{L})$ are the adsorption capacity of creatinine by RAC and the concentration of creatinine at equilibrium conditions. $K_{L}(\mathrm{~L} /$
(A)

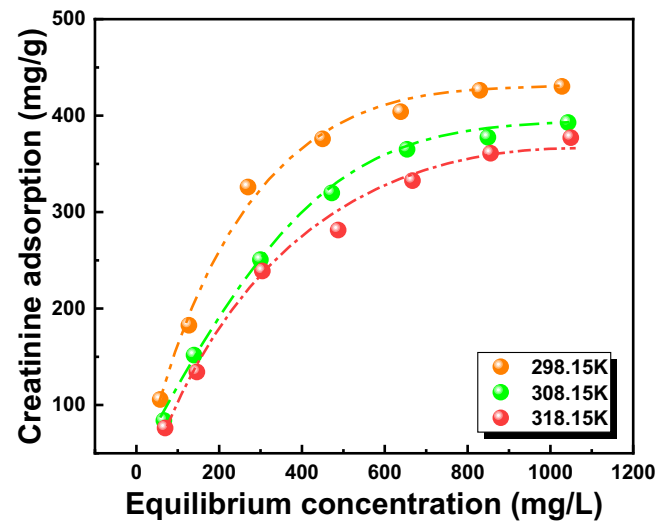

(B)

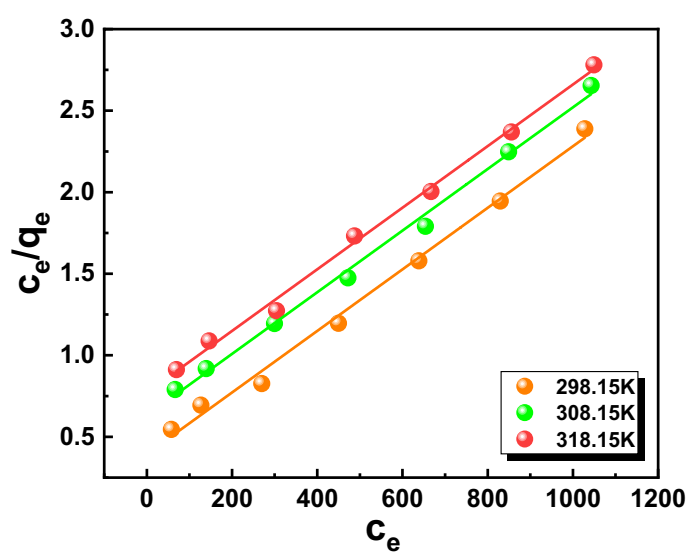

(D)

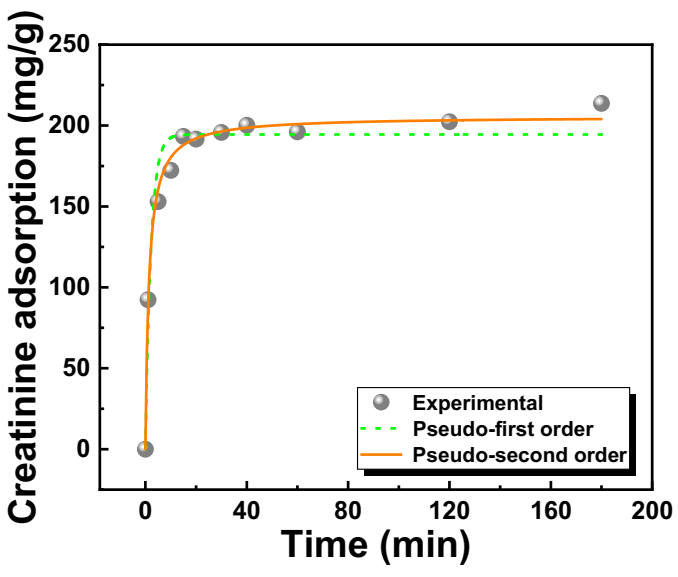

Fig. 4 Adsorption isotherms of creatinine by RAC at three different temperatures (A); Langmuir and Freundlich model fitting curves (B), (C); kinetics for creatinine adsorption on RAC (D) 
$\mathrm{mg}), K_{F}$ and $n$ represent the Langmuir constant, Freundlich constant, and intensity factor, respectively.

The Langmuir isotherm model was developed on the assumptions that adsorbates are adsorbed at a fixed number of energetically equivalent sites and each site can hold only one adsorbate species [45]. Thus, a monolayer of the adsorbate is formed over the adsorbent surface when it gets saturated and the maximum adsorption capacity is achieved. The Freundlich isotherm model assumes that increasing amounts of adsorbate can be adsorbed on the adsorbent surface via multiple layers as the adsorbate concentration increases, and it is widely used to describe heterogeneous systems [46]. Figure 2-C and D show linear fitting curves of Langmuir and Freundlich model. The isotherm data summarized from the Eqs. (3) and (4) at various temperatures are exhibited in Table 2. A comparison of the data verified that the Langmuir isotherm $\left(R^{2}>0.9928\right)$ is more appropriate to represent the uptake behavior than the Freundlich isotherm $\left(R^{2}<0.9217\right)$, indicating the adsorption process of creatinine by RAC is monolayer adsorption. The thermodynamic data are important data to study the changes in the internal energy of adsorption. The $\Delta G^{o}$ (standard Gibbs freeenergy change), $\Delta H^{o}$ (standard enthalpy change), and $\Delta S^{o}$ (the standard entropy change) were investigated to predict the adsorption behavior by Eqs. (5) - (7) [47].

$\Delta G^{o}=\Delta H^{o}-T \Delta S^{o}$

$\ln \left(K_{c}\right)=\Delta S^{o} / R-\Delta H^{o} / R T$

In Eqs. (5) and (6), $R$ and $T$ are the ideal gas constant $(8.314 \mathrm{~J} / \mathrm{mol} \cdot \mathrm{K})$ and temperature in Kelvin $(\mathrm{K})$.

$K_{c}=q_{e} / c_{e}$

In Eq. (7), $q_{e}(\mathrm{mg} / \mathrm{g})$ and $C_{e}(\mathrm{mg} / \mathrm{L})$ are the equilibrium adsorption capacity of creatinine of RAC and the equilibrium adsorption concentration of BPA.

The thermodynamic data of RAC adsorption creatinine is showed in Table 3. The value of $\Delta G^{o}$ was less than 0 at $298.15 \mathrm{~K}, 308.15 \mathrm{~K}$, and $318.15 \mathrm{~K}$, indicating that adsorption is spontaneous due to being thermodynamically favorable. With an increase of temperature, the $\Delta G^{o}$ value kept
Table 3 Thermodynamic parameters for the adsorption of uremic toxin by RAC at different temperatures

\begin{tabular}{llllll}
\hline Toxin & $\mathrm{T}(\mathrm{K})$ & $\ln K_{c}$ & $\begin{array}{l}\Delta G^{o}, \mathrm{~kJ} / \\
\mathrm{mol}\end{array}$ & $\begin{array}{l}\Delta H^{o}, \mathrm{~kJ} / \\
\mathrm{mol}\end{array}$ & $\begin{array}{l}\Delta S^{o}, \mathrm{~J} / \\
(\mathrm{mol} . \mathrm{K})\end{array}$ \\
\hline Creatinine & $298.15 \mathrm{~K}$ & 0.6061 & -1.9178 & -2.0368 & -61.8811 \\
& $308.15 \mathrm{~K}$ & 0.2354 & -1.2990 & & \\
& $318.15 \mathrm{~K}$ & 0.0919 & -0.3182 & & \\
Uric acid & $298.15 \mathrm{~K}$ & 0.6963 & -1.6588 & -9.4622 & -26.1725 \\
& $308.15 \mathrm{~K}$ & 0.4892 & -1.3971 & & \\
& $318.15 \mathrm{~K}$ & 0.4582 & -1.1354 & & \\
\hline
\end{tabular}

increasing, demonstrating that higher temperature hinders the progress of the adsorption process [36]. The $\Delta H^{o}$ value less than zero suggested that the adsorption reaction is a natural exothermic process, which further proved that lower temperature was beneficial to the adsorption behavior [39]. Meanwhile, the negative value of $\Delta S^{o}$ indicated a shift from a three-dimensional state to a two-dimensional state with a more ordered structure at the solid-liquid interface during the creatinine adsorption process [48].

Calculating the adsorption kinetics provides useful insight into the mass transfer mechanism of the adsorption process. Thus, the experimental data has been analyzed by two conventional kinetic formulas, which included pseudofirst-order model and pseudo-second-order model, to investigate the mechanisms of creatinine adsorption by RAC. The pseudo-first-order models could be described as [49]:

$q_{t}=q_{e}\left(1-e^{-K_{1} t}\right)$

In Eq. (2), $q_{t}$ and $q_{e}$ are the creatinine adsorption quantities with RAC at various time points $t$ and at equilibrium $(\mathrm{mg} / \mathrm{g})$, respectively, as well as $k_{1}$ is the pseudo-first-order rate constant $\left(\mathrm{h}^{-1}\right)$.

The pseudo-second-order model could be expressed as:

$q_{t}=K_{2} q_{e}^{2} t /\left(1+K_{2} q_{e} t\right)$

In Eq. (3), $k_{2}\left(\mathrm{~g} \cdot \mathrm{mg}^{-1} \cdot \mathrm{h}^{-1}\right)$ is the rate constant of the pseudo-second-order. The value of $k_{2}$ and $q_{e}$ can be calculated from the intercept and slope of $t / q_{t}$ versus $t$.

Table 2 Isotherm parameters for the adsorption of uremic toxin by RAC

\begin{tabular}{|c|c|c|c|c|c|c|c|}
\hline \multirow[t]{2}{*}{ Toxin } & \multirow[t]{2}{*}{$\mathrm{T}(\mathrm{K})$} & \multicolumn{3}{|c|}{ Langmuir } & \multicolumn{3}{|c|}{ Freundlich } \\
\hline & & $q_{m}$ & $K_{L}$ & $R^{2}$ & $K_{F}$ & $n$ & $R^{2}$ \\
\hline \multirow[t]{3}{*}{ Creatinine } & $298.15 \mathrm{~K}$ & 469 & 0.0011 & 0.9928 & 16.611 & 2.03 & 0.9217 \\
\hline & $308.15 \mathrm{~K}$ & 476 & 0.0015 & 0.9947 & 8.85 & 1.77 & 0.9595 \\
\hline & $318.15 \mathrm{~K}$ & 494 & 0.0018 & 0.9957 & 6.82 & 1.67 & 0.9689 \\
\hline \multirow[t]{3}{*}{ Uric acid } & $298.15 \mathrm{~K}$ & 515 & 0.0305 & 0.9956 & 189.50 & 6.89 & 0.9132 \\
\hline & $308.15 \mathrm{~K}$ & 465 & 0.0300 & 0.9958 & 190.62 & 7.91 & 0.8925 \\
\hline & $318.15 \mathrm{~K}$ & 413 & 0.0634 & 0.9985 & 199.12 & 9.12 & 0.9138 \\
\hline
\end{tabular}


Table 4 Kinetic parameters for the adsorption of uremic toxin by RAC

\begin{tabular}{|c|c|c|c|c|c|c|}
\hline \multirow[t]{2}{*}{ Toxin } & \multicolumn{3}{|c|}{ Pseudo-first-order } & \multicolumn{3}{|c|}{ Pseudo-second-order } \\
\hline & $q_{e}(\mathrm{mg} / \mathrm{g})$ & $k_{1}(1 / \mathrm{h})$ & $R^{2}$ & $q_{e}(\mathrm{mg} / \mathrm{g})$ & $k_{2}\left(\mathrm{~g} \cdot \mathrm{mg}^{-1} \cdot \mathrm{h}^{-1}\right)$ & $R^{2}$ \\
\hline Creatinine & 194 & 0.4604 & 0.9515 & 206 & 0.0035 & 0.9914 \\
\hline Uric acid & 309 & 0.4434 & 0.9680 & 341 & 0.0019 & 0.9957 \\
\hline
\end{tabular}

Figure 3D shows the pseudo-first-order as well as pseudosecond-order kinetics of RAC adsorption creatinine, respectively. The kinetic relative parameters of adsorption are showed in Table 4. From Fig. 4D, it can be known that the adsorption process took place very quickly in the initial contact time $(0 \sim 20 \mathrm{~min})$ and then rapidly reached to the equilibrium state after $30 \mathrm{~min}$, indicating that RAC has rapid creatinine removal efficiency. Normally, the pseudofirst-order and pseudo-second-order kinetics exhibit the information of reaction dynamics and adsorption types, e.g., chemisorption and physisorption [38]. From Fig. 4D, it can be known that the R-square value $\left(R^{2}=0.9914\right)$ of pseudo-second-order was higher than that of the pseudofirst-order model $\left(R^{2}=0.9515\right)$, which indicated that the adsorption process of creatinine might be a chemisorption process (Table 5).

\subsection{Studies of uric acid adsorption behavior}

To explore the applicability of the RAC as an adsorbent for other types of uremic toxins, we carried out experiments to study the adsorption of uric acid by RAC. From Fig. 5A, the adsorption of uric acid by RAC was as high as $504 \mathrm{mg} / \mathrm{g}$ at room temperature $(298.15 \mathrm{~K})$ and showed a decreasing trend as the temperature increased. Similar to adsorption of creatinine, the Langmuir model $\left(R^{2}=9956\right)$ was more consistent with the adsorption process of uric acid than the Freundlich model $\left(R^{2}=0.9132\right)$, indicating that the adsorption of uric acid on the RAC surface remains as a single molecular layer [50]. The change of thermodynamic parameters is still calculated by formulas (5)-(7). The values of $\Delta G^{o}, \Delta H^{o}$, and $\Delta S^{o}$ obtained are displayed in Table 3. The negative values of $\Delta G^{o}$ confirmed

Table 5 Comparison of maximum uremic toxin removal capacity of the various adsorbents

\begin{tabular}{|c|c|c|c|}
\hline \multirow[t]{2}{*}{ Adsorbent } & \multicolumn{2}{|c|}{ Maximum adsorption capacity $(\mathrm{mg} / \mathrm{g})$} & \multirow[t]{2}{*}{ References } \\
\hline & Creatinine & Uric acid & \\
\hline $\mathrm{RAC}$ & 430 & 504 & In this work \\
\hline Spherical activated carbon & 18.4 & 24.3 & [47] \\
\hline Highly mesoporous activated carbons & 68.6 & - & [38] \\
\hline Active carbons with nitric acid hydrothermal Modification & 62.5 & - & {$[15]$} \\
\hline Spherical activated carbon & 18 & 20 & [39] \\
\hline polyaniline-poly (styrene sulfonate) hydrogels based Activated carbon particle & 341.2 & - & [40] \\
\hline Zinc oxide nanoparticles loaded on activated carbon & - & 345.8 & {$[51]$} \\
\hline Pitch-based spherical activated & - & 333.1 & {$[52]$} \\
\hline Carbon nanotubes & 47.2 & - & {$[50]$} \\
\hline Polymeric microsphere & 25 & - & {$[53]$} \\
\hline Three-component dual-layer hollow fiber membrane & 86.2 & 29.3 & [49] \\
\hline Porous polyethersulfone mixed-matrix membranes & 133.3 & - & {$[54]$} \\
\hline Electrospun polyethersulfone/polyvinylpyrrolidone-zeolite core-shell & 4.8 & - & [36] \\
\hline Dealuminated zeolites & 70 & - & {$[55]$} \\
\hline Zeolite-polymer composite nanofibers & 92 & - & {$[56]$} \\
\hline Mordenite & 22 & - & [57] \\
\hline Graphene oxide & 4.1 & - & {$[58]$} \\
\hline Magnetic graphene oxide & & 46.21 & [59] \\
\hline Cellulose dinitrobenzoate & 3.9 & - & {$[60]$} \\
\hline Cellulose nitrate derivatives & 2.1 & - & {$[61]$} \\
\hline $\mathrm{Ti}_{3} \mathrm{C}_{2} \mathrm{~T}_{\mathrm{x}}$ MXene & 45.7 & 17 & [44] \\
\hline $\mathrm{Zn}_{1-\mathrm{x}} \mathrm{Mg}_{\mathrm{x}} \mathrm{Fe}_{2} \mathrm{O}_{4}$ & 77 & 21 & [48] \\
\hline $\mathrm{PEI} / \mathrm{SiO}_{2}$ & - & 84.9 & {$[62]$} \\
\hline
\end{tabular}




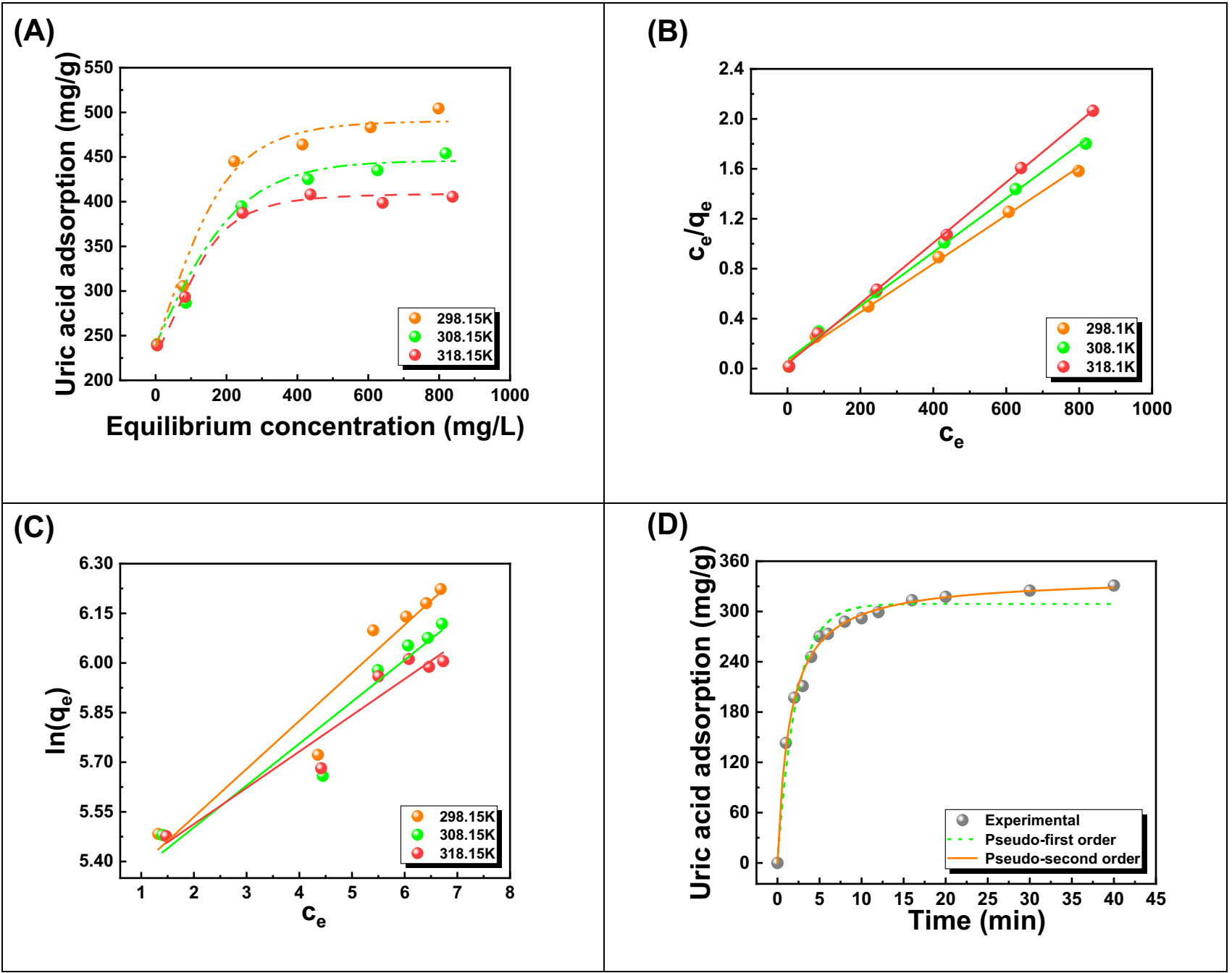

Fig. 5 Adsorption isotherms of uric acid by RAC at three different temperatures (A); Langmuir and Freundlich model fitting curves (B), (C); kinetics for uric acid adsorption on RAC (D)

the spontaneity and feasibility of the adsorption process. Furthermore, $\Delta H^{o}$ with a negative value suggests an exothermic adsorption process [48]. Finally, the negative values of $\Delta S^{o}$ demonstrated the decrease of randomness at the solid-liquid interface during the adsorption process, suggesting that the adsorption of uric acid onto RAC was driven by enthalpy changes. The corresponding linear fitting curves are shown in Fig. 5B-C, and the correlated kinetic adsorption parameters are compiled in Table 4. The correlation coefficients for the pseudo-second-order kinetic model $\left(R^{2}=9957\right)$ are much higher than that for the pseudo-first-order kinetic model $\left(R^{2}=9680\right)$. Moreover, the $q_{e}$ values calculated from the pseudo-second-order kinetic model are much closer to the experimental $q_{e}$ values. Thus, the adsorption kinetics of uric acid onto RAC is better described by the pseudo-second-order model [51].

\subsection{Proposed creatinine and uric acid removal mechanism}

A schematic representation of the adsorption of creatinine and uric acid by RAC was drawn in combination with the characterization of RAC (Fig. 6), experimental data, and kinetic and thermodynamic fitting results to elucidate the multiple interactions between the adsorbent and the adsorbate (Fig. 6): (i) the adsorption has occurred both because of interaction between the creatinine and uric acid dipole and the dipole induced in the porous surface, as well as because of dipole-dipole interaction between surface oxygen groups on the activated carbon surface and the uremic creatinine and uric acid [47]; (ii) the hydroxyl and carbonyl groups on the inner/outer surface of RAC would form with creatinine and uric acid by hydrogen bonding [38]. 


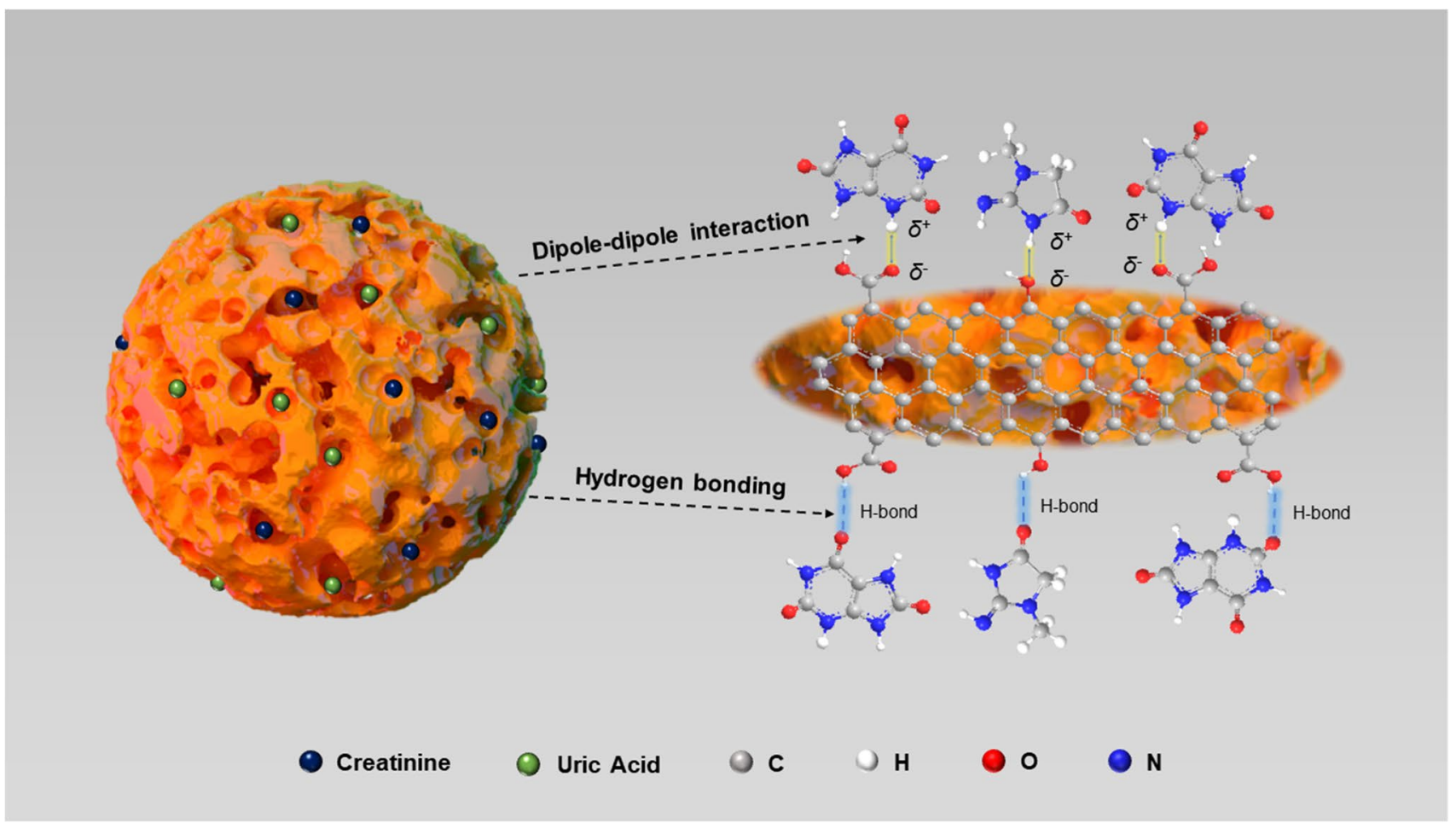

Fig. 6 The proposed adsorption mechanism of RAC for creatinine and uric acid

\section{Conclusion}

We employed RAC to remove creatinine and uric acid from both aqueous solutions, and the batch experiments show ultra-high adsorption capacity (430 and $504 \mathrm{mg} / \mathrm{g}$ for creatinine and uric acid, respectively) compared to other adsorbents. The higher sorbent density could decrease the use of dialysate and the size/weight of the WAK and benefit from relieving pressure on the dialysate supply. The batch experimental, characterization analysis and kinetic, isotherms, and thermodynamic studies co-verified that the removal process of creatinine and uric acid on RAC surface was a spontaneous, exothermic, and monomolecular layer chemisorption process, with adsorption behavior more consistent with the Langmuir model. Finally, it is proposed that the removal of creatinine and uric acid by RAC is an adsorption process with multi-interactions of dipole-dipole interactions and hydrogen bonding.

Funding This work is supported by the National Natural Science Foundation of China (Grant No. 21968014, 22008097), the National Key Research and Development Program of China (Grant No. 2019YFC1805904), and the Analysis and Testing Foundation of Kunming University of Science and Technology (No. 2019T20170031).

\section{References}

1. Hu B, Xie W-1, Wu Y-t, Liu J, Ma S-w, Wang T-p, Zheng S, Lu Q (2021) Mechanism study on the formation of furfural during zinc chloride-catalyzed pyrolysis of xylose. Fuel 295:120656

2. Cheng Y, Luo R, Wang K, Zhang M, Wang Z, Dong L, Li J, Yao Y, Ge S, Xu G (2020) Kidney disease is associated with in-hospital death of patients with COVID-19. Kidney Int 97:829-838

3. Ma Y, Diao B, Lv X, Liang W, Zhu J, Liu L, Zhang S, Shen B, Wang H (2020) COVID-19 in hemodialysis (HD) patients: report from one HD center in Wuhan, China. medRxiv 2020.2002.2024.20027201

4. Kooman JP, Joles JA, Gerritsen KGF (2015) Creating a wearable artificial kidney: where are we now? Expert Rev Med Devices 12:373-376

5. Liyanage T, Ninomiya T, Jha V, Neal B, Patrice HM, Okpechi I, Zhao M-H, Lv J, Garg AX, Knight J, Rodgers A, Gallagher M, Kotwal S, Cass A, Perkovic V (2015) Worldwide access to treatment for end-stage kidney disease: a systematic review. Lancet 385:1975-1982

6. Tang Y, He W, Lu Y, Fielden J, Xiang X, Yan D (2014) Assembly of ruthenium-based complex into metal-organic framework with tunable area-selected luminescence and enhanced photon-to-electron conversion efficiency. J Phys Chem C 118:25365-25373

7. Yan D, Lloyd GO, Delori A, Jones W, Duan X (2012) Tuning fluorescent molecules by inclusion in a metal-organic framework an experimental and computational study. ChemPlusChem 77:1112-1118

8. Murisasco A, Baz M, Boobes Y, Bertocchio P, el Mehdi M, Durand C, Reynier JP, Ragon A (1986) A continuous 
hemofiltration system using sorbents for hemofiltrate regeneration. Clin Nephrol 26(Suppl 1):S53-57

9. Ash SR (2009) Sorbents in treatment of uremia: a short history and a great future. Semin Dial 22:615-622

10. Preliminary safety study of the Automated Wearable Artificial Kidney (AWAK) in Peritoneal Dialysis patients[J]. Peritoneal Dialysis International: Journal of the International Society for Peritoneal Dialysis 2021(11):089686082110192

11. Kameda T, Ito S, Yoshioka T (2017) Kinetic and equilibrium studies of urea adsorption onto activated carbon: adsorption mechanism. J Dispersion Sci Technol 38:1063-1066

12. Kong J, Yue Q, Sun S, Gao B, Kan Y, Li Q, Wang Y (2014) Adsorption of $\mathrm{Pb}$ (II) from aqueous solution using keratin waste - hide waste: Equilibrium, kinetic and thermodynamic modeling studies. Chem Eng J 241:393-400

13. Liu Y, Li K, Wang J, Sun G, Sun C (2009) Preparation of spherical activated carbon with hierarchical porous texture. J Mater Sci 44:4750-4753

14. Safwat SM, Matta ME (2018) Adsorption of urea onto granular activated alumina: a comparative study with granular activated carbon. J Dispersion Sci Technol 39:1699-1709

15. Cao Y, Gu Y, Wang K, Wang X, Gu Z, Ambrico T, Castro MA, Lee J, Gibbons W, Rice JA (2016) Adsorption of creatinine on active carbons with nitric acid hydrothermal modification. J Taiwan Inst Chem Eng 66:347-356

16. Fu Y, Shen Y, Zhang Z, Ge X, Chen M (2019) Activated biochars derived from rice husk via one- and two-step $\mathrm{KOH}-$ catalyzed pyrolysis for phenol adsorption. Sci Total Environ 646:1567-1577

17. Kirtania K, Joshua J, Kassim MA, Bhattacharya S (2014) Comparison of $\mathrm{CO} 2$ and steam gasification reactivity of algal and woody biomass chars. Fuel Process Technol 117:44-52

18. Sun Y, Webley PA (2010) Preparation of activated carbons from corncob with large specific surface area by a variety of chemical activators and their application in gas storage. Chem Eng $\mathbf{J}$ 162:883-892

19. Xia D, Tan F, Zhang C, Jiang X, Chen Z, Li H, Zheng Y, Li Q, Wang Y (2016) ZnCl2-activated biochar from biogas residue facilitates aqueous As(III) removal. Appl Surf Sci 377:361-369

20. Spagnoli AA, Giannakoudakis DA, Bashkova S (2017) Adsorption of methylene blue on cashew nut shell based carbons activated with zinc chloride: the role of surface and structural parameters. J Mol Liq 229:465-471

21. Sathishkumar M, Binupriya AR, Kavitha D, Selvakumar R, Jayabalan R, Choi JG, Yun SE (2009) Adsorption potential of maize cob carbon for 2,4-dichlorophenol removal from aqueous solutions: equilibrium, kinetics and thermodynamics modeling. Chem Eng J 147:265-271

22. Aljeboree AM, Alshirifi AN, Alkaim AF (2017) Kinetics and equilibrium study for the adsorption of textile dyes on coconut shell activated carbon. Arab J Chem 10:S3381-S3393

23. Gecgel U, Kolancilar H (2012) Adsorption of remazol brilliant blue $\mathrm{R}$ on activated carbon prepared from a pine cone. Nat Prod Res 26:659-664

24. Khaled A, El Nemr A, Ei-Sikaily A, Abdelwahab A (2009) Treatment of artificial textile dye effluent containing direct yellow 12 by orange peel carbon. Desalination 238:210-232

25. Hadi S, Taheri E, Amin MM, Fatehizadeh A, Aminabhavi TM (2020) Adsorption of 4-chlorophenol by magnetized activated carbon from pomegranate husk using dual stage chemical activation. Chemosphere 270:128623

26. Mei Y, Xu J, Zhang Y, Li B, Fan S, Xu H (2021) Effect of Fe-N modification on the properties of biochars and their adsorption behavior on tetracycline removal from aqueous solution. Bioresour Technol 325:124732
27. Borhan A, Yusuf S (2020) Activation of rubber-seed shell waste by malic acid as potential $\mathrm{CO} 2$ removal: isotherm and kinetics studies. Materials 13:4970

28. Lee Y, Park J-Y, Lee E-H, Yang J, Jeong B-R, Kim Y-K, Seoh J-Y, Lee S, Han P-L, Kim E-J (2017) Rapid assessment of microbiota changes in individuals with autism spectrum disorder using bacteria-derived membrane vesicles in urine. Experimental Neurobiology 26:307-317

29. Ekrami E, Pouresmaieli M, Barati F, Asghari S, Ziarani FR, Shariati P, Mamoudifard M (2020) Potential diagnostic systems for coronavirus detection: a critical review. Biol Proced Online 22:1

30. Zhao D, Lu Y, Ma D (2020) Effects of structure and constituent of prussian blue analogs on their application in oxygen evolution reaction. Molecules 25:10

31. Shafiq MD, Ismail H (2021) Multifunctional rubber seed biomass usage in polymer technology and engineering: a short review. BioResources 16:4649-4662

32. Borhan A, Yusuf S (2020) Activation of rubber-seed shell waste by malic acid as potential $\mathrm{CO} 2$ removal: isotherm and kinetics studies. Materials 13:21

33. Borhan A, Yusup S, Lim JW, Show PL (2019) Characterization and modelling studies of activated carbon produced from rubberseed shell using $\mathrm{KOH}$ for $\mathrm{CO} 2$ adsorption. Processes 11:855

34. Sheng ZH, Lin S, Chen JJ et al (2011) Catalyst-free synthesis of nitrogen-doped graphene via thermal annealing graphite oxide with melamine and its excellent electrocatalysis[J]. Acs Nano 5(6):4350

35. Cheng J, Gu JJ, Tao W, Wang P, Liu L, Wang CY, Li YK, Feng XH, Qiu GH, Cao FF (2019) Edible fungus slag derived nitrogendoped hierarchical porous carbon as a high-performance adsorbent for rapid removal of organic pollutants from water. Bioresour Technol 294:122149

36. Haghdoost F, Bahrami SH, Barzin J, Ghaee A (2021) Preparation and characterization of electrospun polyethersulfone/polyvinylpyrrolidone-zeolite core-shell composite nanofibers for creatinine adsorption. Sep Purif Technol 257:117881

37. Agarry SE, Owabor CN, Ajani AO (2013) Modified plantain peel as cellulose-based low-cost adsorbent for the removal of 2,6-dichlorophenol from aqueous solution: adsorption isotherms, kinetic modeling, and thermodynamic studies. Chem Eng Commun 200:1121-1147

38. Lupascu T, Petuhov O, Timbaliuc N, Cibotaru S, Rotaru A (2020) Adsorption capacity of vitamin B12 and creatinine on highlymesoporous activated carbons obtained from lignocellulosic raw materials. Molecules 13:3095

39. Kameda T, Horikoshi K, Kumagai S, Saito Y, Yoshioka T (2020) Adsorption of urea, creatinine, and uric acid from three solution types using spherical activated carbon and its recyclability. Chin J Chem Eng 28:2993-3001

40. Jia Y, Li X, Jiang J, Sun K (2015) Adsorption of creatinine on polyaniline-poly(styrene sulfonate) hydrogels based activated carbon particles. Iran Polym J 24:775-781

41. Sun J, He C, Wu L (2010) Structure and properties of PAN-based activated carbon hollow fibers: effect of ammonium dibasic phosphate pretreatment. J Appl Polym Sci 116:2023-2028

42. Zhang H, Guo Y-P, Liu Y-H, Zhao X, Deng Y-H, Wang Z-C, Jiang L (2007) Adsorption of creatinine on porous carbon prepared from rice husk. Acta Phys Chim Sin 23:825-829

43. Li Y, Zhou L, Yang L, Yuan F (2020) Septic shock after liver transplantation successfully treated with endotoxin and cytokine adsorption continuous renal replacement therapy: a case report and literature review. J Int Med Res 48:7

44. Zhao Q, Seredych M, Precetti E, Shuck CE, Harhay M, Pang R, Shan CX, Gogotsi Y (2020) Adsorption of uremic toxins using Ti3C2Tx MXene for dialysate regeneration. ACS Nano 14:11787-11798 
45. Yagub MT, Sen TK, Afroze S, Ang HM (2014) Dye and its removal from aqueous solution by adsorption: a review. Adv Colloid Interface Sci 209:172-184

46. Cheng N, Wang B, Wu P, Lee X, Xing Y, Chen M, Gao B (2021) Adsorption of emerging contaminants from water and wastewater by modified biochar: a review. Environ Pollut 273:116448 ((Barking, Essex : 1987))

47. Kameda T, Horikoshi K, Kumagai S, Saito Y, Yoshioka T (2020) Adsorption of urea, creatinine, and uric acid onto spherical activated carbon. Sep Purif Technol 237:116367

48. Reyes-Rodríguez PY, Ávila-Orta CA, Andrade-Guel M, Cortés-Hernández DA, Herrera-Guerrero A, Cabello-Alvarado C, Sánchez-Fuentes J, Ramos-Martínez VH, Valdez-Garza JA, Hurtado-López GF (2020) Synthesis and characterization of magnetic nanoparticles $\mathrm{Zn1-xMgxFe2O4}$ with partial substitution of $\mathrm{Mg} 2+$ $(x=0.0,0.25,0.5,0.75$ and 1.0$)$ for adsorption of uremic toxins. Ceram Int 46:27913-27921

49. ZainolAbidin MN, Goh PS, Said N, Ismail AF, Othman MHD, Hasbullah H, Abdullah MS, Ng BC, Sheikh Abdul Kadir SH, Kamal F, Mansur S (2020) Co-adsorptive removal of creatinine and urea by a three-component dual-layer hollow fiber membrane. ACS Appl Mater Interfaces 12:33276-33287

50. Ye C, Gong Q, Lu F, Liang J (2007) Adsorption of uraemic toxins on carbon nanotubes. Sep Purif Technol 58:2-6

51. Marahel F, Ghaedi M, Ansari A (2015) Zinc oxide nanoparticles loaded on activated carbon and its application for adsorption removal of uric acid. Synth React Inorg, Met-Org, Nano-Met Chem 45:1387-1395

52. Liu C, Liang X, Liu X, Wang Q, Zhan L, Zhang R, Qiao W, Ling L (2008) Surface modification of pitch-based spherical activated carbon by CVD of NH3 to improve its adsorption to uric acid. Appl Surf Sci 254:6701-6705

53. Gao B, Ying Y, Jian W et al (2010) Preparation and adsorption characteristic of polymeric microsphere with strong adsorbability for creatinine.[J]. J Biochem Mol Toxicol 22(3):166-174

54. Fu C-C, Hsiao Y-S, Ke J-W, Syu W-L, Liu T-Y, Liu S-H, Juang R-S (2020) Adsorptive removal of p-cresol and creatinine from simulated serum using porous polyethersulfone mixed-matrix membranes. Sep Purif Technol 245:116884

55. Koubaissy B, Toufaily J, Yaseen Z, Daou TJ, Jradi S, Hamieh T (2016) Adsorption of uremic toxins over dealuminated zeolites. Adsorpt Sci Technol 35:3-19

56. Takai R, Kurimoto R, Nakagawa Y, Kotsuchibashi Y, Namekawa K, Ebara M (2016) Towards a rational design of zeolite-polymer composite nanofibers for efficient adsorption of creatinine. $\mathrm{J}$ Nanomater 2016:1-7

57. Bergé-Lefranc D, Pizzala H, Denoyel R, Hornebecq V, BergéLefranc J-L, Guieu R, Brunet P, Ghobarkar H, Schäf O (2009) Mechanism of creatinine adsorption from physiological solutions onto mordenite. Microporous Mesoporous Mater 119:186-192

58. Cheng Y-C, Fu C-C, Hsiao Y-S, Chien C-C, Juang R-S (2018) Clearance of low molecular-weight uremic toxins p-cresol, creatinine, and urea from simulated serum by adsorption. J Mol Liq 252:203-210

59. Yilmaz G, Kurtulgu M, Sari MM, Uzun L, Denizli A (2013) Design of magnetic graphene oxide containing magnetically stabilized fluidized bed system for dopamine adsorption in the presence of ascorbic acid and uric acid. Sep Sci Technol 48:2608-2615

60. Adsorption Kinetics and Thermodynamics of Cellulose Dinitrobenzoate Prepared in Ionic Liquid for the Removal Of Creatinine[J] (2015). Bioresources 10(2)

61. Yu J, Wu Y, Wang S, Ma X (2007) The preparation of cellulose nitrate derivatives and their adsorption properties for creatinine. Carbohyd Polym 70:8-14

62. Gao B, Jiang P, Lei H (2006) Studies on adsorption property of novel composite adsorption material $\mathrm{PEI} / \mathrm{SiO} 2$ for uric acid. Mater Lett 60:3398-3404

Publisher's note Springer Nature remains neutral with regard to jurisdictional claims in published maps and institutional affiliations. 